\title{
Pilot study of a training program to enhance transformational leadership in Spinal Cord Injury Peer Mentors
}

\author{
Kathleen A Martin Ginis $\mathbb{D}^{1} \cdot$ Robert B. Shaw ${ }^{1} \cdot$ Matthew J. Stork ${ }^{1}$ Alfiya Battalova ${ }^{2} \cdot$ Christopher B. McBride $^{2}$
}

Received: 22 November 2017 / Revised: 28 February 2018 / Accepted: 5 March 2018

(c) International Spinal Cord Society 2018

\begin{abstract}
Study design Experimental, pragmatic design.

Objectives (1) To determine the effects of a transformational leadership (TFL) training program on spinal cord injury (SCI) peer mentors and their mentees; (2) To document characteristics of mentorship within a community-based SCI peer mentor program. Methods In total 23 SCI peer mentors $(70 \%$ male; Mage $=47.4 \pm 12.1)$ were randomly allocated to an Experimental or Control condition. Experimental condition mentors received a half-day TFL workshop and bi-weekly emailed information on using TFL in SCI peer mentorship. Sixteen SCI mentees $(50 \%$ male; Mage $=49.1 \pm 12.9)$ enrolled in the study and 9 completed measures of self-efficacy and their mentors' use of TFL and supportiveness at 3 and 6-months. Mentors completed monthly reports of mentorship activities.

Setting Community-based peer mentorship program in British Columbia, Canada.

Results There were no between-groups differences in mentee self-efficacy, mentor use of TFL or mentor supportiveness. In the Experimental condition only, total mentorship time and sessions were positively correlated with mentors' use of TFL and supportiveness. Mentorship occurred in-person, by phone, text, and email and mentors discussed an average of 11 topics. Conclusions The intervention did not increase SCI peer mentors' use of TFL relative to a Control condition. Nevertheless, there may be merit in coaching SCI peer mentors to use TFL given the positive correlations between mentorship time and sessions, TFL use, and perceived supportiveness of the mentor. Although inherently challenging, research involving community-based SCI peer mentorship programs provides opportunities for scientists and community organizations to extend knowledge of peer mentorship beyond the context of hospital-based programs.
\end{abstract}

Sponsorship Research supported by a SSHRC Partnership Development Grant.

\section{Introduction}

Spinal cord injury (SCI) peer mentors are individuals who have successfully faced challenges of living with an SCI, and who share their experiences in order to help others adapt and thrive [1-3]. SCI peer mentorship may be delivered within the contexts of in-patient care, out-patient care, or in the community [4]. People who receive SCI peer mentorship (i.e., mentees) report various physical, social and psychological benefits of the mentorship [4-7]. Although little is known about how to maximize these

Kathleen A Martin Ginis

kathleen_martin.ginis@ubc.ca

University of British Columbia, Kelowna, Canada

2 Spinal Cord Injury BC, Vancouver, Canada benefits, recent research suggests a linkage between SCI peer mentors' displays of transformational leadership (TFL) and positive outcomes in their mentees [8].

TFL is a leadership style that has been shown to cultivate positive changes in the thoughts, feelings and behaviors of those being led [9-11]. TFL consists of four related behaviors: (1) Idealized Influence-engendering trust and respect of others and acting as a role model; (2) Inspirational Motivation-showing enthusiasm and optimism about what others can accomplish, articulating a compelling vision of the future; (3) Intellectual Stimulation-engaging the rationality of others and getting them to look at old problems in new ways; and (4) Individualized Consideration-demonstrating care and concern for others' physical and psychological needs [9]. In a recent qualitative study involving SCI peer mentors, mentees reported a greater sense of relatedness with their mentors, and increased motivation, self-confidence, hope, and 
participation when they perceived that their mentors displayed TFL [8]. These results suggest there may be value in training SCI peer mentors to use TFL.

Field-based experiments have shown that TFL can be developed in business, military and educational leaders through training, and result in adaptive outcomes for those being led $[12,13]$. However, no study to date has tested the effects of TFL training in a peer mentorship context. Thus, the primary purpose of this pilot study was to examine the effects of a TFL training program on SCI peer mentors and their mentees within the context of an existing, communitybased SCI peer mentorship program.

A recent study of a community-based SCI peer mentorship program revealed that the effects of peer mentorship on participation and life satisfaction may not emerge until years, or even decades, post-mentorship. Furthermore, mentees' feelings of relatedness and competence were shown to mediate those effects [14]. Given these results, we focused on change in indicators of the relatively proximal outcomes of relatedness (i.e., mentor supportiveness) and competence (i.e., self-efficacy). It was hypothesized that mentees receiving mentorship from TFL-trained peer mentors would perceive their mentors to use TFL more frequently, rate the mentorship relationship as more supportive and report greater self-efficacy than adults receiving mentorship from mentors who were not TFL-trained.

A secondary purpose was to document characteristics of SCI mentor-mentee interactions. Although characteristics of hospital-based SCI peer mentorship programs [15, 16] have been reported, we are unaware of any studies documenting the extent to which community-based SCI peer mentors and mentees typically interact (i.e., duration or frequency of mentorship), the media through which interactions occur, level of satisfaction with the relationship, and topics discussed. As such, preliminary data were collected on these variables. We also tested for associations between the total duration and number of interactions and mentees' perceptions of, and responses to, the mentorship.

\section{Methods}

\section{Participants}

Recruitment was facilitated by SCI British Columbia (SCI $\mathrm{BC}$ ), a not-for-profit organization that provides communitybased peer mentoring services for people with SCI (weekly and monthly peer coffee groups, peer matches for a single 2-h meeting, and long-term peer mentoring [17]). The organization's Peer Coordinator contacted all peer mentor members $(n=25)$ and provided a study information sheet outlining the purpose of the study (to examine if TFL training "has an impact on how you mentor and, in turn, any
Table 1 Characteristics of Mentors and Mentees Who Enrolled and Completed the Study

\begin{tabular}{|c|c|c|c|c|}
\hline & \multicolumn{2}{|c|}{ Enrolled $(n=39)$} & \multicolumn{2}{|c|}{ Completed $(n=18)$} \\
\hline & $\begin{array}{l}\text { Mentors } N \\
=23\end{array}$ & $\begin{array}{l}\text { Mentees } N \\
=16\end{array}$ & $\begin{array}{l}\text { Mentors N } \\
=9\end{array}$ & $\begin{array}{l}\text { Mentees } N \\
=9\end{array}$ \\
\hline Age (years) & $\begin{array}{l}47.7 \pm \\
12.09\end{array}$ & $\begin{array}{l}49.13 \pm \\
12.98\end{array}$ & $\begin{array}{l}52.22 \pm \\
12.61\end{array}$ & $\begin{array}{l}45.78 \pm \\
12.10\end{array}$ \\
\hline $\begin{array}{l}\text { Years post } \\
\text { injury }\end{array}$ & $\begin{array}{l}15.74 \pm \\
10.63\end{array}$ & $\begin{array}{l}11.87 \pm \\
11.41\end{array}$ & $\begin{array}{l}15.44 \pm \\
8.65\end{array}$ & $\begin{array}{l}12.67 \pm \\
9.55\end{array}$ \\
\hline \multicolumn{5}{|l|}{ Sex } \\
\hline Male & $16(69.6)$ & $8(50)$ & $5(55.6)$ & $4(44.4)$ \\
\hline Female & $7(30.14)$ & $8(50)$ & $4(44.4)$ & $5(55.6)$ \\
\hline \multicolumn{5}{|l|}{ Level of injury } \\
\hline Paraplegia & $7(30.14)$ & $8(50)$ & $4(44.4)$ & $4(44.4)$ \\
\hline Tetraplegia & $16(69.6)$ & $8(50)$ & $5(55.6)$ & $5(55.6)$ \\
\hline \multicolumn{5}{|l|}{ Injury severity } \\
\hline Complete & $13(56.5)$ & $4(25)$ & $5(55.6)$ & $3(33.3)$ \\
\hline Incomplete & $10(43.5)$ & $11(68.8)$ & $4(44.4)$ & $6(66.7)$ \\
\hline \multicolumn{5}{|l|}{ Mobility Aid } \\
\hline $\begin{array}{l}\text { Manual } \\
\text { wheelchair }\end{array}$ & 17 (73.9) & $4(25)$ & $8(88.9)$ & $3(33.3)$ \\
\hline $\begin{array}{l}\text { Power } \\
\text { wheelchair }\end{array}$ & $4(17.4)$ & $6(37.5)$ & $1(11.1)$ & $4(44.4)$ \\
\hline Gait Aid & 0 & $4(25)$ & 0 & $2(22.2)$ \\
\hline Nothing & $2(8.7)$ & $2(12.5)$ & 0 & 0 \\
\hline \multicolumn{5}{|l|}{ Ethnicity } \\
\hline White & $21(91.3)$ & $7(43.58)$ & $8(88.9)$ & $4(44.4)$ \\
\hline $\begin{array}{l}\text { Native } \\
\text { Canadian }\end{array}$ & 0 & $2(12.5)$ & 0 & 0 \\
\hline Asian & $2(8.7)$ & $5(31.3)$ & $1(11.1)$ & $4(44.4)$ \\
\hline Other & 0 & $2(12.5)$ & 0 & $1(11.1)$ \\
\hline \multicolumn{5}{|l|}{ Marital status } \\
\hline Single & $10(43.5)$ & $6(37.5)$ & $3(33.3)$ & $2(22.2)$ \\
\hline Common law & $1(4.3)$ & $1(6.3)$ & 0 & 0 \\
\hline Married & $9(39.1)$ & $6(37.5)$ & $4(44.4)$ & $5(55.6)$ \\
\hline Divorced & $3(13)$ & $3(18.8)$ & $2(22.2)$ & $2(22.2)$ \\
\hline \multicolumn{5}{|c|}{ Highest level of education } \\
\hline High school & $2(8.7)$ & $2(12.5)$ & 0 & $2(22.2)$ \\
\hline College & $8(34.8)$ & $5(31.3)$ & $3(33.3)$ & $2(22.2)$ \\
\hline University & $7(30.4)$ & $7(43.8)$ & $3(33.3)$ & $5(55.6)$ \\
\hline Postgrad & $5(21.7)$ & $2(12.5)$ & $3(33.3)$ & 0 \\
\hline $\begin{array}{l}\text { Years } \\
\text { Mentoring }\end{array}$ & $5.04 \pm 4.72$ & & $4.49 \pm 4.46$ & \\
\hline $\begin{array}{l}\text { Number of } \\
\text { Mentees }\end{array}$ & $\begin{array}{l}12.82 \pm \\
24.26\end{array}$ & & $\begin{array}{l}15.53 \pm \\
21.14\end{array}$ & \\
\hline
\end{tabular}

effects on the clients that you work with"), the time commitment, and remuneration. Those who expressed interest were then scheduled to be contacted by a researcher who obtained informed consent. To recruit mentees, individuals 
Table 2 Measures Administered to the Mentees

\begin{tabular}{|c|c|}
\hline Measure & Description \\
\hline Demographics & $\begin{array}{l}\text { Information was collected on each participant's age, sex, ethnicity, education, marital status, date of } \\
\text { injury, primary mode of mobility, injury level and injury completeness }\end{array}$ \\
\hline Self-efficacy & $\begin{array}{l}\text { The } 16 \text {-item scale Moorong Self-Efficacy Scale [30] was administered. It is an SCI-specific } \\
\text { measure of self-efficacy for performing everyday activities. Responses to each item were made on a } \\
7 \text {-point scale }(1=\text { very uncertain; } 7=\text { very certain). Psychometric validation in a Canadian sample } \\
\text { of adults with SCI revealed a } 3 \text {-factor structure consisting of three subscales: interpersonal, } \\
\text { instrumental, and participation self-efficacy [31]. In the present study, total scores were computed } \\
\text { for each subscale. However, Cronbach's alpha for the Participation subscale was }<0.40 \text {, so it was } \\
\text { excluded from analyses }\end{array}$ \\
\hline Mentor supportiveness & $\begin{array}{l}\text { A modified version of the 6-item version (http://selfdeterminationtheory.org/pas-health-care-clima } \\
\text { te/) of Williams et al.'s [32] Health Care Climate Questionnaire [HCCQ] was used to assess mentor } \\
\text { supportiveness. The HCCQ was designed to assess the degree to which patients perceive their } \\
\text { health care providers, physicians or counselors as being autonomy supportive. For the purpose of } \\
\text { the present study, the language of the six HCCQ items was modified from references to 'my health- } \\
\text { care providers' to 'my peer counsellor/mentor'. In response to input from our community partners, } \\
\text { a 7th item was added querying perceived trust in the peer counsellor/mentor. Items were rated on a } \\
7 \text {-point scale ( } 1=\text { strongly disagree; } 7=\text { strongly agree) and summed to create a total scale score. } \\
\text { At both measurement points, Cronbach's alpha was }>0.70\end{array}$ \\
\hline $\begin{array}{l}\text { Mentors' Use of Transformational } \\
\text { Leadership }\end{array}$ & $\begin{array}{l}\text { A modified version of the } 16 \text {-item Transformational Teaching Questionnaire [33] (TTQ) was used } \\
\text { to assess the extent to which mentees perceived their mentors to display TFL. The TTQ was } \\
\text { modified by changing the item stem/prefix of "My physical education teacher..." with "My peer } \\
\text { mentor...". One item on the Individualized Consideration subscale ("tries to know every student in } \\
\text { the class") could not be modified and was deleted, resulting in a } 15 \text {-item measure. Responses to } \\
\text { each item were made on a } 5 \text {-point scale }(0=\text { not at all; } 4=\text { frequently). Cronbach's alpha for all } \\
\text { four subscales was }>0.70 \text { at both measurement points }\end{array}$ \\
\hline
\end{tabular}

contacting SCI BC for peer mentorship were invited to participate. Only mentees who were matched with a mentor enrolled in the study were included. SCI BC has its own criteria for mentor-mentee matching; consequently, not every mentee who contacted SCI BC was solicited for the study, and not all enrolled mentors were matched with mentees. While challenging for recruitment, this strategy ensured that the research protocol did not interfere with the normal standard of service provided by SCI BC. Enrolled mentees who had been matched with one of the enrolled mentors were scheduled for a telephone interview with a researcher who obtained informed consent. Mentor and mentee participants were remunerated with cash and gift cards, respectively.

Twenty-three SCI peer mentors provided informed consent and demographic information. Mentors were stratified by gender and randomly allocated, by draw, to an Experimental $(n=13)$ or waitlist Control $(n=10)$ condition. Sixteen mentees consented to participate and completed a demographic questionnaire and baseline assessment of selfefficacy. Participant demographics and baseline data are presented in Table 1.

\section{Study protocol}

This pilot study was designed with a pragmatic intent [18]; it was undertaken in a real world context and under the usual circumstances of SCI BC's peer mentorship program, for the purpose of informing an evidence-based decision on whether to implement TFL training in that program [19]. An experimental design was used.

Mentors in the Experimental condition participated in a half-day, in-person training workshop, led by a TFL expert. The workshop was interactive and included a presentation with slides and videos, and an accompanying workbook. Topics covered in the workshop included: an overview of leadership styles; what is TFL and why it is important; descriptions of each TFL behavior followed by interactive and role playing activities to develop practical strategies for the use of that TFL behavior with mentees; discussion of potential barriers, challenges and solutions to using each TFL behavior during mentee interactions; setting goals for the use of TFL; and a discussion on the types of resources and support that the mentors wanted to receive from the research team as they implemented their new knowledge about TFL into their mentorship. An abridged version of the workshop, modified to be relevant to peer mentorship in physical activity contexts [20], is available at https://www. youtube.com/watch $? \mathrm{v}=$ PwbIrEDGsa0 \& feature $=$ youtu.be

After the workshop, mentors were matched with mentees by the SCI BC Peer Coordinator. SCI BC peer matches are made primarily on similarity of (a) life experiences and background/life situations and (b) injury level. For instance, if a person with quadriplegia seeks mentorship for support 
Fig. 1 Data Collection Procedures for Mentees

\begin{tabular}{|c|c|}
\hline $\begin{array}{l}\text { Measurement } \\
\text { Time-Point }\end{array}$ & Experimental Condition Measures \\
\hline Baseline & $\begin{array}{l}\text { Demographic Questionnaire } \\
\text { SCI-Specific Self-Efficacy }\end{array}$ \\
\hline 3-Months & $\begin{array}{c}\text { SCI-Specific Self-Efficacy Scale } \\
\text { Health Care Climate Questionnaire } \\
\text { Transformational Mentoring } \\
\text { Questionnaire }\end{array}$ \\
\hline 6-Months & $\begin{array}{c}\text { Health Care Climate Questionnaire } \\
\text { SCI-Specific Self Efficacy Scale } \\
\text { Transformational Mentoring } \\
\text { Questionnaire }\end{array}$ \\
\hline
\end{tabular}

Control Condition Measures

Demographic Questionnaire SCI-Specific Self-Efficacy Scale

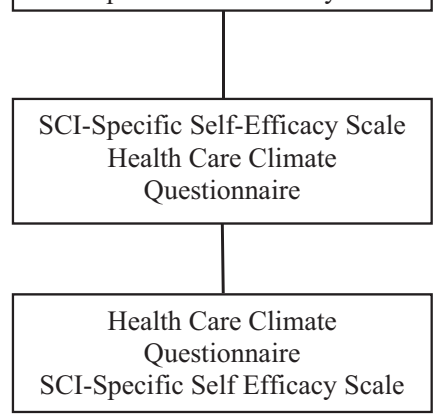

with parenting young children, the Peer Coordinator tries to create a match with a mentor who has experience parenting young children and a similar injury. Priority is placed on matching based on experiences and challenges [17]. As per SCI BC's standard practices, mentors and mentees facilitated their own interactions and were given complete autonomy over their mentoring relationships (e.g., meeting frequency, discussion topics, relationship duration). Every two weeks, Experimental condition mentors received emails with information on how to apply TFL in SCI peer mentorship. Control condition mentors received articles from previous SCI BC publications, that were unrelated to peer mentorship.

Each month, a staff member of SCI BC (4th author), contacted mentors by telephone to administer a standardized assessment of mentorship activities undertaken by each mentor who had been matched with a mentee. The staff member was blinded to the mentors' allocated condition. Mentors reported the number of contacts with their mentees, total time spent mentoring, modes of interaction (e.g., phone, email), and the topics discussed during interactions that month. At 3 and 6-months, mentors were asked to rate their level of satisfaction with their relationship with their mentee on a scale ranging from 1 (very dissatisfying) to 6 (very satisfying).

Mentees were contacted by a researcher at 3-months and 6-months to complete the measures described in Table 2. Mentees and researchers were blinded to the mentors' allocated condition. To minimize first-order carryover effects, measures were administered in a counterbalanced order, using a Williams Square design [21]. Data collection and management were facilitated using FluidSurveys (http://fluidsurveys.com). A detailed description of the data collection time points and measures is provided in Figs. 1 and 2. The protocol was not registered as a clinical trial because it did not include health outcome measures [22].

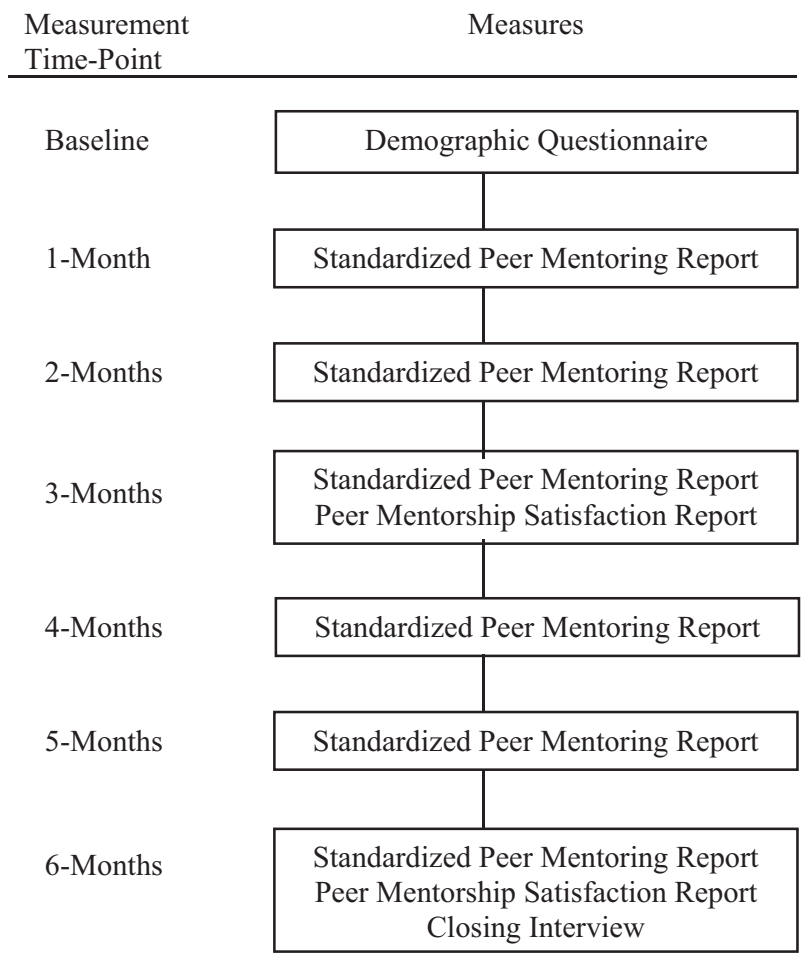

Fig. 2 Data Collection Procedures for Mentors

\section{Analyses}

Using data collected from mentees, independent samples $t$ tests were conducted to compare self-efficacy, perceived supportiveness of the mentor, and mentors' use of TFL, between the Experimental and Control conditions. Cohen's $d$ effect sizes were computed and interpreted as $0.20,0.50$, and 0.80 indicating small, medium, and large effects, respectively [23]. Paired-samples $t$-tests were computed to determine if changes in self-efficacy occurred within either condition. 


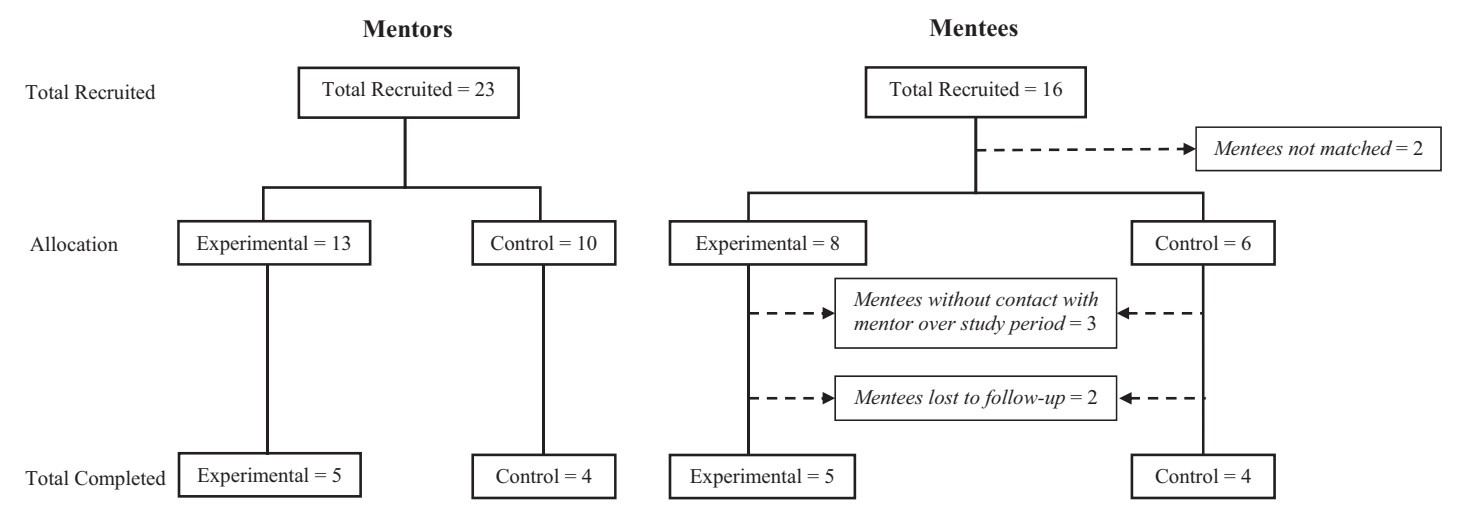

Fig. 3 Flow of Mentor and Mentee Recruitment and allocation

Table 3 Descriptive Statistics for Mentees' Perceptions of Mentor Supportiveness, Mentor Use of TFL, and Mentee Self-Efficacy

\begin{tabular}{|c|c|c|c|c|c|c|}
\hline & \multirow[b]{2}{*}{ Baseline } & \multicolumn{2}{|c|}{ Experimental $(n=5)$} & \multirow[b]{2}{*}{ Baseline } & \multirow[b]{2}{*}{$3 \mathrm{mos}$} & \multirow{2}{*}{$\begin{array}{l}\text { Control }(n=4) \\
6 \mathrm{mos}\end{array}$} \\
\hline & & $3 \mathrm{mos}$ & $6 \mathrm{mos}$ & & & \\
\hline Mentor Supportiveness & & $42.40 \pm 5.68$ & $39.44 \pm 7.86$ & & $38.50 \pm 10.79$ & $39.55 \pm 5.75$ \\
\hline TFL-Idealized Influence & & $13.00 \pm 2.45$ & $12.60 \pm 3.05$ & & $13.00 \pm 1.63$ & $12.75 \pm 2.63$ \\
\hline TFL-Inspirational Motivation & & $12.02 \pm 3.08$ & $12.00 \pm 3.74$ & & $11.50 \pm 3.32$ & $13.00 \pm 2.16$ \\
\hline TFL-Intellectual Stimulation & & $10.44 \pm 2.42$ & $9.87 \pm 4.31$ & & $10.25 \pm 4.42$ & $10.75 \pm 4.27$ \\
\hline TFL-Individualized Consideration & & $8.40 \pm 2.61$ & $7.80 \pm 2.86$ & & $7.50 \pm 2.38$ & $6.00 \pm 2.45$ \\
\hline Interpersonal Self-Efficacy & $17.00 \pm 2.24$ & $16.80 \pm 2.77$ & $15.60 \pm 1.52$ & $19.75 \pm 1.50$ & $19.50 \pm 1.29$ & $19.00 \pm 2.31$ \\
\hline Instrumental Self-Efficacy & $17.20 \pm 2.86$ & $16.00 \pm 3.74$ & $16.40 \pm 3.36$ & $19.83 \pm 1.46$ & $18.75 \pm 1.71$ & $19.75 \pm 1.26$ \\
\hline
\end{tabular}

For Mentor Supportiveness, scores could range from 7 to 49

For all TFL measures except Individualized Consideration, scores could range from 0 to 16

For Individualized Consideration, scores could range from 0 to 12

For the Self-Efficacy measures, scores could range from 4 to 28

Using data collected from mentors, independent samples $t$-tests were used to compare total number of mentor-mentee interactions, hours spent on mentorship, and satisfaction with the mentorship relationship between the two conditions. Frequencies were computed for modes of interaction and topics discussed. Finally, one-tailed Pearson correlation coefficients were computed to determine if total mentorship interactions and hours were associated with the mentee outcome measures. Because data were nested (i.e., mentees nested within mentors), separate correlations were computed for each condition to avoid violating the assumption of independence of observations. To minimize the number of correlations and reduce risk of a Type 1 error, only the 6-month data were used in these analyses. Six-month rather than 3-month data were used because the full intervention (i.e., bi-weekly mailouts) had not been delivered until 6-months and we wanted mentors to have adequate time to develop and use the TFL behaviors.

\section{Results}

\section{Participant flow}

Participant flow through the study protocol is depicted in Fig. 3. Characteristics of those who were enrolled $(n=39)$ and completed $(n=18)$ the study are presented in Table 1.

\section{Mentee outcomes}

As shown in Table 3, the conditions did not differ on the measures of perceived supportiveness of the mentorship relationship, or mentors' use of TFL at 3-months or 6months (all $p \mathrm{~s}>0.35, d \mathrm{~s}<0.68$ ). Control condition mentees tended to have nonsignificantly higher self-efficacy than Experimental condition mentees at baseline 3 and 6months ( $d$ s ranged from 0.95 to 1.74), but there was no change in self-efficacy over time for either condition $(p s>0.16)$. 
Table 4 Mentorship Characteristics as Reported by Mentors

\begin{tabular}{lll}
\hline & Experimental condition $(n=5)$ & Control condition $(n=4)$ \\
\hline Number of Interactions & $20.60 \pm 16.23$ & $9.25 \pm 3.04$ \\
Time spent mentoring (h) & $11.73 \pm 9.02$ & $4.89 \pm 3.37$ \\
Satisfaction with relationship (3 months) & $4.40 \pm 1.14$ & $3.75 \pm 2.06$ \\
Satisfaction with relationship (6 months) & $4.60 \pm 1.34$ & $3.00 \pm 1.41$ \\
\hline
\end{tabular}

For satisfaction with relationship, scores could range from 1 to 6 .

Table 5 Number of Mentors Reporting Each Mode of Interaction

\begin{tabular}{llll}
\hline Mode of interaction & \multicolumn{2}{l}{ Condition } & \\
\cline { 2 - 4 } & Experimental & Control & Total \\
\hline Email/Text & 5 & 3 & 8 \\
In Person, One-on-one & 3 & 2 & 5 \\
Phone & 2 & 2 & 4 \\
In Person, Group & 0 & 2 & 2 \\
Skype & 1 & 0 & 1 \\
\hline
\end{tabular}

\section{Mentorship characteristics}

Experimental condition mentors tended to report more interactions with their mentees and more total time mentoring over the 6-months than Control condition mentors (Table 4). However, these large differences $(d=0.97,1.00)$ were not statistically significant, $p s>0.18$. Likewise, Experimental condition mentors tended to be more satisfied with the relationship at 3 and 6-months than Control mentors (Table 4), but these medium-large differences were not statistically significant $\left(p s>0.13, d_{3 \operatorname{mos}}=0.39, d_{6 \mathrm{mos}}=\right.$ 1.16).

With regard to mode of interaction, mentors and mentees interacted using email/text messaging, in person (one-onone and group), over the phone, and through Skype (Table 5). All nine mentors interacted with their mentees during the first two months of the study. Only three mentors reported interacting with their mentees through all 6 months (Table 6). On average, the mentor-mentee relationships lasted about four months $(\mathrm{M}=4.22, \mathrm{SD}=1.64)$.

In total 24 different topics were discussed (see Table 7), with an average of 11 topics $(\mathrm{M}=11.56, \mathrm{SD}=3.68$, range $=4-17$ ). The most frequently cited topics were recreation/ hobbies/traveling, self-care/daily living, and exercise/sports/ leisure time physical activity.

Table 6 Frequency of Mentor-Mentee Interactions

\begin{tabular}{|c|c|c|c|c|c|c|c|c|}
\hline \multirow{2}{*}{$\begin{array}{l}\text { Mentor } \\
\text { condition }\end{array}$} & & \multicolumn{7}{|c|}{ \# of interactions } \\
\hline & & Month1 & Month2 & Month3 & Month4 & Month5 & Month6 & Total \\
\hline \multicolumn{9}{|c|}{ Experimental } \\
\hline Mentor 1 & & 8 & 8 & 4 & 7 & 1 & 2 & 30 \\
\hline Mentor 2 & & 10 & 5 & 8 & 4 & 7 & 4 & 38 \\
\hline Mentor 3 & & 2 & 1 & 0 & 0 & 1 & 0 & 4 \\
\hline Mentor 4 & & 2 & 1 & 12 & 2 & 4 & 6 & 27 \\
\hline \multirow[t]{3}{*}{ Mentor 5} & & 3 & 1 & 0 & 0 & 0 & 0 & 4 \\
\hline & Total \# of Interactions & 25 & 16 & 24 & 13 & 13 & 12 & 103 \\
\hline & $\begin{array}{l}\text { Total time spent } \\
\text { mentoring (hours) }\end{array}$ & 17.08 & 15.00 & 8.83 & 7.00 & 6.00 & 4.75 & 58.67 \\
\hline \multicolumn{9}{|l|}{ Control } \\
\hline Mentor 6 & & 8 & 3 & 1 & 0 & 0 & 0 & 12 \\
\hline Mentor 7 & & 2 & 4 & 1 & 2 & 0 & 0 & 9 \\
\hline Mentor 8 & & 3 & 2 & 5 & 1 & 0 & 0 & 11 \\
\hline \multirow[t]{3}{*}{ Mentor 9} & & 2 & 1 & 0 & 1 & 1 & 0 & 5 \\
\hline & Total \# of Interactions & 15 & 10 & 7 & 4 & 1 & 0 & 37 \\
\hline & $\begin{array}{l}\text { Total time spent } \\
\text { mentoring (hours) }\end{array}$ & 9.00 & 4.25 & 3.30 & 2.67 & 0.33 & 0.00 & 19.55 \\
\hline
\end{tabular}


Table 7 Topics Discussed During Peer Mentorship

\begin{tabular}{|c|c|}
\hline Topics discussed & $\begin{array}{l}\text { \# of mentors who discussed } \\
\text { topic with their mentee }\end{array}$ \\
\hline Recreation/Hobbies/Traveling & 8 \\
\hline Self-care/Daily living & 8 \\
\hline $\begin{array}{l}\text { Exercise/Sports/Leisure Time } \\
\text { Physical Activity }\end{array}$ & 8 \\
\hline $\begin{array}{l}\text { Medical Supplies/Equipment } \\
\text { Issues }\end{array}$ & 7 \\
\hline Transportation & 7 \\
\hline Pain/Recovery & 6 \\
\hline Accessible Housing & 6 \\
\hline Parenting & 6 \\
\hline Community Resources & 5 \\
\hline Attitudinal Barriers & 5 \\
\hline Employment & 4 \\
\hline Family/Relationships & 4 \\
\hline Vocational Issues & 4 \\
\hline Caregiving & 4 \\
\hline Life Planning & 4 \\
\hline Volunteering & 3 \\
\hline Education & 3 \\
\hline Sexuality & 3 \\
\hline Next Meeting Logistics & 2 \\
\hline General Information & 2 \\
\hline $\begin{array}{l}\text { Community Involvement/ } \\
\text { Sociability }\end{array}$ & 2 \\
\hline Physiotherapy/Massage Therapy & 1 \\
\hline Cooking/Healthy Living & 1 \\
\hline Immigration & 1 \\
\hline
\end{tabular}

\section{Relationships between mentorship time and frequency and mentee outcomes}

In the Experimental condition, as total mentorship time and number of interactions increased, so did mentees' perceptions of the supportiveness of the mentor and their perceptions of the extent to which their mentors used TFL (all $r s>0.78, p s<0.059$; see Table 8). In the Control condition, no consistent pattern of relationships emerged. Correlations ranged from $r=-0.97$ to $r=0.71$, and the only relationship that achieved statistical significance was in the opposite direction hypothesized (see Table 8). Neither hours of mentorship, nor number of interactions, were significantly correlated with mentee self-efficacy in either condition.

\section{Discussion}

Contrary to our hypothesis, SCI peer mentors who received TFL training did not display more TFL compared to mentors in a Control condition. Furthermore, mentees of TFLtrained mentors did not report feeling more supported or self-efficacious than mentees assigned to mentors in the Control condition. These results may indicate that more effective training is needed to affect change in TFL. Alternatively, given evidence that experienced SCI peer mentors inherently use TFL [24], and scores on most of the TFL subscales were relatively high, ceiling effects may have limited the potential for post-training improvements. A next research step may be to test a more intensive TFL training program with inexperienced mentors.

Table 8 One-tailed Bivariate Correlations Between Mentorship Time and Interactions, and Mentees' Perceptions of Mentor Supportiveness, TFL Use and Self-Efficacy

\begin{tabular}{|c|c|c|c|c|c|c|c|c|c|}
\hline & 1 & 2 & 3 & 4 & 5 & 6 & 7 & 8 & 9 \\
\hline $\begin{array}{l}\text { 1. Total Time with } \\
\text { Mentor }\end{array}$ & - & -0.859 & -0.175 & 0.411 & 0.068 & 0.657 & 0.705 & 0.490 & 0.883 \\
\hline $\begin{array}{l}\text { 2. Number of } \\
\text { Interactions }\end{array}$ & $0.958 * *$ & - & -0.216 & -0.399 & -0.399 & -0.800 & $-0.967 *$ & -0.839 & -0.834 \\
\hline $\begin{array}{l}\text { 3. Mentor } \\
\text { Supportiveness }\end{array}$ & 0.802 & 0.781 & - & -0.607 & $0.967 *$ & 0.618 & 0.426 & 0.704 & 0.254 \\
\hline 4. TFL-II & $0.944 * *$ & $0.981 * *$ & $0.865^{*}$ & - & 0.763 & 0.853 & 0.414 & 0.549 & 0.781 \\
\hline 5. TFL-IM & $0.987 * *$ & $0.922 *$ & 0.769 & $0.920 *$ & - & 0.795 & 0.567 & 0.802 & 0.491 \\
\hline 6. TFL-IS & $0.880^{*}$ & $0.810^{*}$ & $0.904 *$ & $0.889^{*}$ & $0.909^{*}$ & - & 0.828 & 0.878 & $0.915^{*}$ \\
\hline 7. TFL-IC & $0.900^{*}$ & $0.956 * *$ & $0.850 *$ & $0.991 * *$ & $0.887 *$ & $0.888 *$ & - & $0.943 *$ & 0.757 \\
\hline $\begin{array}{l}\text { 8. Interpersonal } \\
\text { Self-Efficacy }\end{array}$ & 0.415 & 0.551 & 0.497 & 0.497 & 0.264 & 0.168 & 0.438 & - & 0.688 \\
\hline $\begin{array}{l}\text { 9. Instrumental } \\
\text { Self-Efficacy }\end{array}$ & 0.089 & 0.219 & -0.405 & 0.044 & 0.040 & -0.346 & 0.010 & 0.284 & - \\
\hline
\end{tabular}

TFL Transformational Leadership, II Idealized Influence, IM Inspirational Motivation, IS Intellectual Stimulation, IC Individualized Consideration Correlations for Control participants $(n=4)$ are presented above the diagonal, and correlations for Experimental participants $(n=5)$ are presented below the diagonal $* p<0.059 ; * *<0.01$ 
It should be noted, however, that in the Experimental condition only, total mentorship time and interactions were significantly and positively correlated with both displays of TFL and with the extent to which mentees perceived the relationship to be supportive. Although it is possible that the narrower range of interaction values for the Control mentors undermined our ability to detect significant correlations in that condition, perhaps with greater mentor-mentee contact, TFL-trained mentors would have had more opportunity to practice and display newly-learned TFL behaviors. These displays, coupled with more opportunities to share information, could translate into mentees feeling more supported.

The absence of between or within-groups effects on selfefficacy is contrary to reports of a medium-sized effect of SCI peer mentorship on self-efficacy at 180 days postdischarge [7]. However, the authors of that report assessed self-efficacy for managing self-care needs and community integration, which they cited as common themes during inpatient mentorship interactions. We administered standardized assessments of interpersonal and instrumental selfefficacy to our sample of community-dwelling mentees using the Moorong self-efficacy scale. Items on this scale aligned with the topics most often discussed during mentorship (e.g., self-care, recreation, family relationships). However, changes in self-efficacy for one behavior do not typically generalize to other behaviors [25]. Because the Moorong self-efficacy scale aggregates self-efficacy scores across several behaviors, it would be difficult to detect changes in self-efficacy scores for activities/behaviors discussed during mentorship if scores for those activities were aggregated with scores for activities not discussed and for which self-efficacy did not change. An important direction for future research, is to develop appropriate and psychometrically sound measures that can detect mentorship effects on mentees. Furthermore, given the pragmatic nature of our study, the topics discussed during mentorship were not controlled. To properly test the effects of SCI peer mentorship on mentee self-efficacy, it may be necessary to conduct experiments in which the mentorship topic is controlled (e.g., exercise) and aligned with measures of selfefficacy for that topic (e.g., exercise barrier and task selfefficacy [26]).

Differences in the amount of mentorship received could also explain differences in self-efficacy outcomes between our study and previous research [7]. In the previous study, mentorship was implemented weekly throughout the inpatient stay and for 90 days post-discharge, with participants receiving an average of 26 sessions. In the present study, mentees received an average of only 9 (Control) or 21 (Experimental) interactions, and the total duration of all interactions averaged about $34 \mathrm{~min}$. Mentors may need to spend more time with mentees in order to influence selfefficacy.

By conducting this pilot study in a community-based program, we were able to identify some mentorship characteristics that may be different from hospital-based mentorship. Identifying such differences is important for scientists wanting to conduct studies in these contexts, and for organizations implementing peer mentorship in different settings. First, whereas hospital-based peer mentorship interactions are typically face-to-face or by telephone [27, $28,7]$, most mentors in the present study interacted through text or email. In fact, two mentors had no face-to-face or phone contact whatsoever with their mentees. Such differences likely reflect greater autonomy of community-based mentors and mentees, as well as transportation and other barriers to meeting face-to-face. Research is needed to determine if electronic communications (e.g., e-mail, text) facilitate the same quality of mentorship as face-to-face or telephone-based interactions.

Second, although many topics discussed by communitybased peer mentors were consistent with topics discussed by hospital-based mentors (e.g., self-care/daily living, employment, sexuality) [15, 16], some uniquely community-relevant topics emerged (e.g., volunteering, immigration). Identifying these topics can help prioritize information to be taught in community-based mentorship training programs. Third, whereas mentoring relationships initiated in hospital settings may last from 1 month to 5 years or longer [3, 8, 10], most mentors in our study reported no further communication with mentees after 4 months. Collecting the reasons for terminating communication (e.g., resolution of the issue for which mentorship was sought, the quality of the match, mentor availability) could improve the design and implementation of mentorship programs.

Despite extending knowledge on SCI peer mentorship beyond hospital-based programs, our community-based study faced several challenges and has limitations. In particular, it was a challenge to recruit mentees into the study and match them with appropriate mentors. Research on the most important matching characteristics would be valuable to support SCI peer mentor programs in facilitating mentor-mentee matches. Recruitment and matching challenges were compounded by dropouts and loss to followup; consequently, the sample size was smaller than anticipated, which limited our analyses and conclusions. Furthermore, to avoid interfering with the program's standard of service, aspects of the mentorship were not controlled (e.g., frequency, duration, modes of communication). While this pragmatic approach allowed for collection of valuable naturalistic data on community-based mentorship, it introduced numerous confounds into the design. Finally, because mentors and mentees were not matched until after the 
training session, it was not possible to obtain a true baseline measure of mentors' displays of TFL. Although unlikely, it is possible that TFL increased from baseline to 3- and 6months but these changes were not captured.

Recognizing these limitations, we tentatively conclude that the single training session and emailed prompts implemented in this study were insufficient to change SCI peer mentors' use of TFL. This finding runs contrary to research conducted in an educational context, whereby a one-day TFL training session followed by delivery of readings on TFL, improved teachers' use of TFL [29]. However, the positive correlations between mentorship frequency and duration, the use of TFL, and the perceived supportiveness of the mentor suggest there may be some merit in coaching mentors to use TFL in their peer mentorship interactions. Although inherently challenging, research involving community-based SCI peer mentorship programs provides opportunities for scientists and community organizations to accrue knowledge of peer mentorship that extends beyond the context of hospital-based programs.

Funding The funding agency had no involvement whatsoever in the conception or preparation of this manuscript.

\section{Compliance with ethical standards}

Conflict of interest The authors declare that they have no conflict of interest.

\section{References}

1. Hernandez B, Hayes E, Balcazar F, Keys C. Responding to the needs of the underserved: a peer-mentor approach. SCI Psychosoc Process. 2001;14:142-9.

2. Holt NL, Hoar SD. The multidimensional construct of social support. In: Hanton S, Mellalieu S, editors. Literature reviews in sport psychology. Hauppauge, NY: Nova Science Publishers; 2006. p. 199-225.

3. Sherman JE, DeVinnery DJ, Sperling KB. Social support and adjustment after spinal cord injury: Influence of past peermentoring experiences and current live-in partner. Rehabil Psychol. 2004;49:140-9.

4. Divanoglou A, Georgiou M. Perceived effectiveness and mechanisms of community peer-based programmes for Spinal Cord Injuries: a systematic review of qualitative findings. Spinal Cord. 2017;55:225-34. https://doi.org/10.1038/sc.2016.147

5. Sweet SN, Noreau L, Leblond J, Martin Ginis KA. Peer support need fulfillment among adults with spinal cord injury: relationships with participation, life satisfaction and individual characteristics. Disabil Rehabil. 2016;38:558-65.

6. Houlihan BV, Everhart-Skeels S, Gutnick D, Pernigotti D, Zazula J, Brody M, et al. Empowering adults with chronic spinal cord injury to prevent secondary conditions. Arch Phys Med Rehabil. 2016;97:1687-1695. https://doi.org/10.1016/j.apmr.2016.04.005.

7. Gassaway J, Jones ML, Sweatman WM, Hong M, Anziano P, DeVault K. Effects of peer mentoring on self-efficacy and hospitalization readmission after inpatient rehabilitation of individuals with spinal cord injury: a randomized controlled trial. Arch Phys Med Rehabil. 2017;98:1526-34. https://doi.org/10.1016/j.apmr. 2017.02.018.

8. Beauchamp MR, Scarlett LJ, Ruissen GR, Connelly CE, McBride $\mathrm{CB}$, Casemore $\mathrm{S}$, et al. Peer mentoring of adults with spinal cord injury: a transformational leadership perspective. Disabil Rehabil. 2016;38:1884-92. 1107773.

9. Bass BM, Riggio RE. Transformational leadership. 2nd ed. Mahwah, NJ: Erlbaum; 2006.

10. Howell JM, Avolio BJ. Transformational leadership, transactional leadership, locus of control, and support for innovation: key predictors of consolidated business-unit performance. J Appl Psychol. 1993;78:891-902.

11. Sosik JJ, Avolio BJ, Kahai SS. Effects of leadership style and autonomy on group potency and effectiveness in a group decision support system environment. J Appl Psychol. 1997;82:89-103.

12. Dvir T, Eden D, Avolio BJ, Shamir B. Impact of transformational leadership on follower development and performance: a field experiment. Acad Manag J. 2002;45:735-44.

13. Barling J, Weber T, Kelloway EK. Effects of transformational leadership training on attitudinal and financial outcomes: a field experiment. J Appl Psychol. 1996;81:827-32.

14. Sweet SN, Michalovic E, Latimer-Cheung AE, Fortier M, Noreau L, Zelaya W, et al. Spinal cord injury peer mentorship: applying self-determination theory to explain quality of life and participation. Arch Phys Med Rehabil. 2018;99:468-76.

15. Ljungberg I, Kroll T, Libin A, Gordon S. Using peer mentoring for people with spinal cord injury to enhance self-efficacy beliefs and prevent medical complications. J Clin Nurs. 2011;20:351-8.

16. Veith EM, Sherman JE, Pellino TA, Yasui NY. Qualitative analysis of the peer-mentoring relationship among individuals with spinal cord injury. Rehabil Psychol. 2006;51:289-98.

17. Spinal Cord Injury BC. The peer support program: what is the peer support program? 2018. https://sci-bc.ca/what-we-do/peersupport-program/. Accessed Feb 122018.

18. Ford I, Norrie J. Pragmatic trails. New Engl J Med. 2016;375:454-63. https://doi.org/10.1056/NEJMra1510059.

19. Loudon K, Treweek S, Sullivan F, Cheesbrough G, Donnan P, Thorpe KE, et al. The PRECIS-2 tool: Designing trials that are fit for purpose. Br J Med. 2015;350:2147 https://doi.org/10.1136/ bmj.h2147

20. Salci LE, Perrier MJ, Ginis S, Martin Ginis KA. Active Living Leaders Training Program for adults with spinal cord injury: a pilot study. Spinal Cord. 2016;54:662-9. https://doi.org/10.1038/ sc. 2015.168

21. Williams EJ. Experimental designs balanced for the estimation of residual effects of treaments. Aust J Sci Res. 1949;2:149-68.

22. International Committee of Medical Journal Editors. Clinical Trial Registration. 2017. http://icmje.org/recommendations/browse/ publishing-and-editorial-issues/clinical-trial-registration.html.

23. Cohen J. A power primer. Psychol Bull. 1992;112:155-9.

24. Shaw RB, McBride CB, Casemore S, Martin Ginis KA. Transformational mentoring: leadership behaviours of spinal cord injury peer mentors. Rehabil Psychol. 2018;63:131-40.

25. Bandura A. Self-Efficacy: The Exercise of Control. New York: Freeman; 1997.

26. Latimer-Cheung AE, Arbour-Nicitopoulos KP, Brawley LR, Gray C, Wilson AJ, Prapavessis H, et al. Developing physical activity interventions for adults with spinal cord injury. Part 2: Motivational counseling and peer-mediated interventions for people intending to be active. Rehabil Psychol. 2013;585:307-15.

27. Carpenter C, Forwell SJ, Jongbloed LE, Backman CL. Community participation after spinal cord injury. Arch Phys Med Rehabil. 2007;88:427-33. 
28. Boschen KA, Tonacki M, Gargaro J. Long-term adjustment and community reintegration following spinal cord injury. Int $\mathrm{J}$ Rehabil Res. 2003;26:157-64.

29. Beauchamp MR, Barling J, Morton KL. Transformational teaching and adolescent self-determined motivation, self-efficacy, and intentions to engage in leisure time physically activity: a randomized controlled pilot trial. Appl Psychol: Health Well-Being. 2011;3:127-50.

30. Middleton JW, Tate RL, Geraghty TJ. Self-efficacy and spinal cord injury: psychometric properties of a new scale. Rehabil Psychol. 2003;48:281-8. https://doi.org/10.1037/0090-5550.48.4. 281.
31. Brooks J, Smedema SM, Tu WM, Eagle D, Catalano D, Chan F. Psychometric validation of the Moorong Self-Efficacy Scale in people with spinal cord injury: a brief report. Rehabil Couns Bull. 2014;58:54-7. https://doi.org/10.1177/0034355214523506.

32. Williams GC, Grow VM, Freedman ZR, Ryan RM, Deci EL. Motivational predictors of weight loss and weight-loss maintenance. J Pers Soc Psychol. 1996;70:115-26. https://doi.org/10. 1037/0022-3514.70.1.115

33. Beauchamp MR, Barling J, Li J, Morton KL, Keith SE, Zumbo BD. Development and psychometric properties of the transformational teaching questionnaire. $J$ Health Psychol. 2010;15:1123-34. https://doi.org/10.1177/1359105310364175. 